\title{
Alteration in Antioxidant Defense System and Oxidative Stress in blood for Non Alcoholic Fatty Liver Disease
}

\author{
A.P. Thakkar ${ }^{1}$, H.J. Shah ${ }^{2 *}$, N.D. Patel ${ }^{3}$, J.G. Shah ${ }^{4}$ \\ ${ }^{1}$ Dept. of Biochemistry, M. B. Patel Science College, Affiliated to Sardar Patel University, Anand, India \\ ${ }^{2 *}$ Dept. of Biochemistry, M. B. Patel Science College, Affiliated to Sardar Patel University, Anand, India \\ ${ }^{3}$ Jiwandeep Hospital, Anand, India \\ ${ }^{4}$ National Dairy Development Board (NDDB), Anand, India \\ *Corresponding Author: hjsapt@gmail.com, Tel.: +91 8488867567, +91 9925929699
}

Available online at: www.isroset.org

Received $12^{\text {th }}$ Aug 2017, Revised $28^{\text {th }}$ Aug 2017, Accepted $18^{\text {th }}$ Sep 2017, Online $30^{\text {th }}$ Oct 2017

\begin{abstract}
Antioxidants neutralize free radicals or reactive oxygen species which cause oxidative stress. Oxidative stress is a major contributor in the pathogenesis of Non-alcoholic fatty liver disease (NAFLD). Present study is aimed to know level of antioxidant defense system and oxidative stress in controls and NAFLD participants. The cross-sectional study was carried out at tertiary centre of gastroenterologist unit at Anand. Experimental participants were divided into two groups: Control ( $\mathrm{n}=52$,

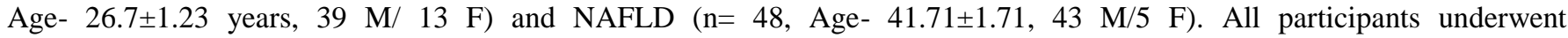
anthropometric assessment, clinical examination, biochemical parameters, antioxidant parameters and lipid peroxidation marker or oxidative stress marker (MDA- Malondialdehyde). Results of our study indicate significant increase in markers of metabolic syndrome (obesity, dyslipidaemia) and liver enzymes in NAFLD compared to controls. Total antioxidant activity (Gallic acid equivalent (GAE ( $\mathrm{p}=0.0008)$ ) and Trolox equivalent $(\mathrm{TE}(\mathrm{p}<0.0001)$ ) and antioxidant enzymes such as superoxide dismutase (SOD ( $\mathrm{p}=0.0023))$, Glutathione Peroxidase (GSHPx $(\mathrm{p}<0.0001))$, Glutathione-s-transferase $(\mathrm{GST}(\mathrm{p}<0.0001))$ and Catalase (CAT $(\mathrm{p}<0.0001))$ were significantly decreased in NAFLD compared to controls. Lipid peroxidation marker or oxidative stress marker (MDA) was significantly increased $(\mathrm{p}<0.0001)$ in NAFLD compared to controls. Our study concludes that NAFLD participants have increased oxidative stress and decreased antioxidant levels compared to controls. Study strongly indicates that antioxidant enzymes namely GST and CAT can be used as surrogate markers of oxidative stress for NAFLD participants.
\end{abstract}

Keywords- Anthropometric Assessment; Biochemical Parameters; Oxidative Stress Marker; Total Antioxidant Activity; Antioxidant Enzymes.

\section{ABBRIVATIONS}

NAFLD: non-alcoholic fatty liver disease

BMI: body mass index

WBC: white blood cells

RBC: red blood cells

FBS: fasting blood glucose

HDL: high density lipoprotein

LDL: low density lipoprotein

SGPT: serum glutamate pyruvate transaminase

\section{INTRODUCTION}

Non-alcoholic fatty liver disease (NAFLD) is defined as steatosis affecting $>5 \%$ of hepatocytes in the absence of excessive significant alcohol consumption. The histological spectrum of NAFLD includes non-alcoholic fatty liver (NAFL; steatosis without hepatocellular injury), steatohepatitis (NASH; steatosis with inflammation and hepatocyte ballooning degeneration), fibrosis and ultimately
SGOT: serum glutamic oxaloacetic transaminase GGT: $\Upsilon$-glutamyl transferase

ALP: alkaline phosphatase

GAE: gallic acid equivalent

TE: trolox equivalent

ROS: reactive oxygen species

HCC: hepatocellular carcinoma

cirrhosis [1]. NAFLD has become the most common cause of chronic liver disease worldwide in the last three decades and a major cause of liver- related morbidity and mortality.

Clinical burden of NAFLD is not only confined to liverrelated morbidity and mortality, but there is a growing evidence that NAFLD is a multi-system disease, affecting several extra-hepatic organs like kidney, lung and heart etc. $[2,3]$. 
NAFLD can occur at all ages, the highest prevalence is at the age of $40-50$ years [4]. The majority $(56 \%-79 \%)$ of NAFLD participants are overweight or obese (BMI (body mass index) $>25 \mathrm{~kg} / \mathrm{m}^{2}$ ), only one third have the metabolic syndrome. Sometimes lean participants (BMI $<25 \mathrm{~kg} / \mathrm{m}^{2}$ ) also have metabolic risk factors for NAFLD [5].

Prevalence of NAFLD is inadequately known due to absence of signs, symptoms and lacks sensitive and specific diagnostic tools $[4,6]$. Most individuals with NAFLD are usually asymptomatic, however, sometimes fatigue, discomfort in the right upper quadrant of the abdomen is observed [5-8]. In India, prevalence of NAFLD is around 9\% to $32 \%$ of general population with higher prevalence (57$74 \%$ ) in those with overweight/obesity and with diabetes/ pre-diabetes [4]. In western countries, the prevalence of NAFLD varies between 20 to $30 \%$, rising up to $70-90 \%$ in obese individuals $[7,9,10]$.

The pathogenesis of NAFLD is a very complicated process and model proposed in 2010 known as "multiple parallel hits" which includes obesity, insulin resistance and oxidative stress as a causative factors for onset of NAFLD [11]. Insulin resistance has a central role in both steatosis and in its progression to more advanced forms of the disease as non-alcoholic steatohepatitis (NASH) makes it the main pathogenic mechanism of NAFLD [12]. Oxidative stress, result of excess amount of ROS production regarded as one of the pathological mechanisms that results in initiation and progression of various liver diseases such as alcoholic liver diseases and non-alcoholic fatty liver disease to fibrosis, cirrhosis and Hepatocellular Carcinoma [13].

Liver enzymes namely SGPT, SGOT, GGT are reported as a surrogate marker for liver disease, but they are non-specific because up to $78 \%$ of the NAFLD individuals possess normal values for liver enzymes and do not reliably correlate with liver histology [5-7]. Even though Ultrasonography is a commonly used method for prognosis of NAFLD with sensitivity of $85 \%$, it cannot detect stages of fibrosis and inflammation [6]. Liver biopsy is useful invasive method for detection of stages of NAFLD progression from steatosis, NASH to cirrhosis and it is known as "gold standard method" for detection of fibrosis, but has low accuracy and is assessed with complications [6, 14]. Review studies suggest that approximately $30 \%$ of the general population have radiological evidence of steatosis, $8 \%$ have raised transaminases due to NAFLD and remaining sufferers go unrecognised [1].

The human body is equipped with a variety of highly sophisticated and complex antioxidant protection system to protect the cells and organ systems of the body against reactive oxygen species (ROS) [15]. Antioxidant activity is known to reflect the altered redox balance of affected fluids, tissues or organs in several pathological processes [16]. Increased antioxidant status can reduce the risk for chronic diseases including liver diseases, cardiovascular diseases, cancer, neurodegenerative diseases, and immune dysfunction [17].

Enzymatic Antioxidants have ability to catalyse free radical quenching reactions, convert free radicals into non-reactive species [15, 17]. They are important in preventing lipid peroxidation and maintaining the structure and function of biologic membranes [18].

Reactive oxygen species present in excessive amounts may cause extreme damage to biomolecules such as lipids, proteins, and DNA [17]. "The imbalance between oxidants and antioxidants in favour of the oxidants, potentially leading to damage", termed as "oxidative stress" [19]. Oxidative stress is among the major causative factors in induction of many chronic and degenerative diseases including atherosclerosis, ischemic heart disease, aging, diabetes mellitus, cancer, immunosuppression, neurodegenerative diseases, male infertility, liver diseases, vitiligo and others $[13,19,20]$. Oxidative stress is a process to explain progression to hepatocellular damage, inflammation and fibrosis [21]. Lipid peroxidation caused by oxidative stress is implicated in the pathogenesis of several hepatic disorders in human [22]. Damage to cells caused by free radicals is believed to play a central role in disease progression [15].

Oxidative stress due to augmented generation of reactive oxygen species (ROS) can induce lipid peroxidation leading to inflammation and fibrogenesis through the activation of stellate cells [23, 24]. Fibrosis as a precursor of cirrhosis is a pivotal pathological process in the evolution of all chronic liver diseases to cirrhosis [25]. Hepatic fibrosis is fibrous scarring of the liver. Hepatic fibrosis itself causes no symptoms but can lead to the end-stage cirrhosis [26].

NAFLD condition may alter the level of antioxidants because of oxidative stress which are undertaken for the investigation. Review studies do not show sequential and integrated work for total antioxidant activity, antioxidant enzyme system and lipid peroxidation marker from human blood samples for NAFLD participants.

Literature reviewed cannot suggest any parameter which gives clear idea regarding onset or stages of fatty liver disease. Many researchers studied selected parameters of antioxidants and only limited information is available to conclude the presence of liver disease which cannot be considered as a strong evaluation parameter. Therefore, present study is aimed to analyse the level of plasma /serum antioxidants status and oxidative stress marker (MDA) in NAFLD condition. Systematic study includes taking informed consent from selected participants followed by blood collection and lab analysis of selected parameters. Parameters selected were antioxidant activity, antioxidant enzymes (SOD, GR, GST, GSHPx, CAT) and lipid peroxidation marker (MDA). Investigation of our study point out that as oxidative stress increases, total antioxidant activity and antioxidant enzymes decreases which is specific for selected parameters. Present study helps to diagnose the 
fatty liver condition at the very early stage of NAFLD using analytical blood values for selected parameters. Our study recommends that similar research can be carried out for both the genders and at different geographical condition. Our study concludes that GST and CAT can be used as surrogate markers for NAFLD participants.

\section{RELATED WORK}

Many researchers have separately worked on selected total antioxidant activities [27, 28] or selected antioxidant enzymes [18, 28 - 32] or oxidative stress marker [28, 29] from miscellaneous mammalian plasma /serum samples. Very little sequential work is found on total antioxidant activity, selected antioxidant enzymes (SOD, Catalase, GSHPx, GR and GST) and oxidative stress marker (MDA) from the human plasma /serum sample in NAFLD condition compared to the controls which is limited for only selected parameters. Therefore, present study was planned to analyse total antioxidant activity, all sequential antioxidant enzymes and lipid peroxidation marker from blood samples of each, i.e. controls and NAFLD participants.

\section{MATERIALS AND METHODS}

\section{Study Design:}

All participants underwent anthropometric assessment, clinical examination, biochemical parameters, antioxidant parameters and oxidative stress marker.

\section{Participant recruitment procedure: \\ Inclusion Criteria:}

Cross-sectional study includes NAFLD and controls recruited from tertiary centre of gastroenterologist unit, Anand. Controls $(n=52)$ [Participants with normal clinical examination, no symptoms, normal vital signs and has normal biochemical parameters such as blood glucose, lipid profile, liver function test, kidney function test, free of infection at least 30 days prior to the study] and NAFLD participants $(n=48)$ [Participants with inflammation and without inflammation- [1) Non-alcoholic, 2) without chronic viral hepatitis as well as known etiologies of liver disease and 3) elevated aminotransferases level, 4) Ultrasonographic findings] were considered for the study.

\section{Exclusion Criteria:}

Pregnant and lactating women, Alcoholic, Smokers/ tobacco users, Exposure to radiation, Exposure to ozone therapy or hyperbaric oxygen therapy, Exposure to heavy metals or ayurvedic medicine, Infection within 30 days, Cancer, Cardiac, gastro-intestinal and brain ischemic disease, Currently not using antioxidant drugs which affect the oxidative stress and antioxidant status were excluded.

\section{Informed Consent:}

Explain interest of the study to the participants and informed consent were taken.

Anthropometric assessment and clinical parameters and biochemical parameters

Anthropometric assessment includes the record for age, height and weight (Height was measured using height board which is fixed to the wall and weight using high quality electronic digital scale). BMI was calculated using formula $\mathrm{BMI}=$ [body weight $(\mathrm{kg})] /\left[\right.$ (height) $\left.\left.(\mathrm{m})^{2}\right)\right][33]$.

Measurement of blood pressure (Systolic/Diastolic$(120 / 80))$ was done by sphygmomanometers.

Blood $(6-7 \mathrm{ml})$ was collected from all the participants at fasting condition in plain and EDTA bulb with the help of the laboratory expert. Blood samples were centrifuged at 3000rpm for $5 \mathrm{~min}$ to separate serum and plasma. Collected samples were analysed immediately for all enzymes, remaining were kept at $4^{\circ} \mathrm{C}$ for other respective parameters. Analysis of the remaining parameters were completed within a week.

Hemogram (Hemoglobin, TC (WBC, RBC and platelets)), Fasting blood glucose, Total Protein, albumin, globulin, lipid parameters such as Cholesterol, TG, LDL, HDL and liver enzymes (SGPT, SGOT, ALP, GGT) were analysed using standard protocols in reputed laboratory.

\section{Antioxidant parameters and oxidative stress marker}

Total antioxidant activity (Gallic acid equivalent and Trolox equivalent) [34] and enzymatic antioxidants (SOD [35], GSHPx [36], GR [37], CAT [38] and GST [39] were analysed using standard protocol in our laboratory after cross-checking the standards and samples. U.V. Spectrophotometer (Systronic- model no. 117) was used for investigation of all the above parameters. MDA was analysed from plasma by standard method [40].

\section{Statistical analysis}

Data are expressed as mean \pm S.E. and percentages. Statistical analysis was conducted using $\mathrm{z}$ - test and $\mathrm{t}$ - test [41].

\section{Ethical approval:}

The institutional ethics committee approved the study protocol.

\section{RESULTS AND DISCUSSION}

Anthropometric assessment, clinical parameters and biochemical parameters

In this cross-sectional study, controls and NAFLD participants were studied for anthropometric assessment, clinical parameters and biochemical parameters. Values are presented in table: 1 . The prevalence of NAFLD increases with the rising incidence of obesity. In our study $50 \%$ and $29 \%$ of the NAFLD participants were obese and overweight 
respectively. Population and hospital-based studies from the West India also reported around $10-24 \%$ of general population and $57-74 \%$ of obese individuals suffering from NAFLD [5]. Our study indicates presence of metabolic syndrome such as high BMI, dyslipidaemia or/and elevated liver enzyme levels (SGPT, SGOT and GGT) compared to controls. Results of our study were in agreement with the study carried out on human participants suffering from NAFLD condition. [42, 43]. Almost 90\% of NAFLD participants have more than one characteristic of metabolic syndrome [12].

\section{Antioxidant parameters and oxidative stress marker}

Antioxidant parameters such as total antioxidant activity (Gallic acid equivalent and Trolox equivalent) and antioxidant enzymes (SOD, GSHPx, GST and CAT) were decreased in NAFLD participants compared to controls. Antioxidant parameters such GST activity [49].

as total antioxidant activity (Gallic acid equivalent and Trolox GST (4.02-6.46 vs. 0.005-1.78) and CAT (0.24-0.98 vs. equivalent), antioxidant enzymes (SOD, GSHPx, GR, GST and 0.002-0.1) values in controls vs. NAFLD are highly CAT) decreases may be due to defences against free radical- significant $(\mathrm{p}<0.0001)$ so GST and CAT were considered as mediated injury includes enzymatic deactivation and direct most sensible parameters to know oxidative stress in reaction with free radicals [18].

Result of our study for total antioxidant activity was significantly decreased in NAFLD compared to controls [Gallic acid equivalent (46\% vs. 34\%) and Trolex equivalent (67\% vs. $24 \%)$ ] depicted in figure: 1 . Compared to reference value $[44,45]$ total antioxidant status was found lower for controls, which further decreases (GAE $(P=0.0008)$, TE $(P<0.0001))$ among NAFLD participants. Previous study carried out for NAFLD participants also reveal decrease in total antioxidant activity [28].

Antioxidant enzymes such as SOD, GSHPx, GST and CAT decreased in NAFLD compared to controls are as presented in figure: 2.

Decreased activity of SOD is important factor for pathogenesis of NASH [46]. Our study revealed significant lower value for SOD in controls compared to reported value, which further significantly decreased $(p=0.0023)$ in NAFLD participants. SOD is considered as the first line of defence against oxygen derived free radicals, converts superoxide anion into $\mathrm{H}_{2} \mathrm{O}_{2}$, forming as neutral products $\mathrm{O}_{2}$ and $\mathrm{H}_{2} \mathrm{O}$. SOD scavenges superoxide and inhibits the formation of Peroxynitrite, thereby suppressing the resulting injury. Therefore, it acts as a protective mechanism against tissue injury. SOD level decreases with increase in injury due to higher the utilization of SOD in defence mechanism [24].

GSHPx catalyses reductive destruction of hydrogen and lipid hydro peroxides, using glutathione as an electron donor [18]. Study carried out by few researchers found decrease in SOD and GSHPx activity which is in accordance with our results $[28,16]$. Initial level of SOD and GSHPx is lower in controls may be due to lower intake of antioxidant containing foods. Decrease in the activity of glutathione peroxidase may be due to exhaustion or inactivation of the enzyme by reactive oxygen species, since oxidative damage to hemoglobin and cell membrane has been reported to reduce the activity of glutathione peroxidase [47].

Finding of our study indicates non- significant alteration in GR activity for NAFLD participants compared to controls [18].

Our study indicates a significant $(\mathrm{p}<0.0001)$ decrease in the activity of catalase in NAFLD participants compared to controls may be due to less availability of NADPH [29, 47]. The function of GST is to detoxify foreign compounds. GST in plasma provides an exceptionally sensitive index of hepatocellular damage. Serum GST may be a more sensitive marker of hepatocellular damage than transaminases [48]. Our study also indicates significant decrease $(\mathrm{p}<0.0001)$ in

GST activity for NAFLD participants compared to controls (100\% vs. 0\%). Study carried out on liver tissue of wistar NAFLD. Both enzymes can be used as surrogate marker to know oxidative stress in NAFLD.

Oxidative stress due to increased ROS production has a role in the pathogenesis of NAFLD [46]. Liver is continuously exposed to ROS and is protected from oxidative injury by a range of antioxidant pathways [18]. Oxidative stress has inverse co-relationship with antioxidant status. Result of our study indicates decrease in antioxidant enzyme activity with increase in oxidative stress among NAFLD compared to controls which resemble with the reported studies carried out for NAFLD participants [16, 28, 29, 35, 50-52]. Comparison of oxidative stress marker and antioxidant enzymes is highlighted in figure: 3 .

Increase in oxidative stress leads to worsen the condition from fatty liver to fibrosis and cirrhosis. ROS contributes to the fibrotic process by enhanced inflammation, which activates various cytokines and various growth factors like TGF- $\beta 1$, which leads to fibrosis or regeneration. The fibrotic action of TGF- $\beta 1$ has ability to suppress expression of antioxidant enzymes [53]. Fibrosis in NAFLD is the only strongest predictive factor for liver related mortality due to conversion of fibrosis to cirrhosis and HCC [54]. The evaluation of ROS and antioxidant enzymes at an early stage is important, which helps to prevent long term progression of NAFLD condition.

Statistical analysis for antioxidant parameters such as total antioxidant activity (Gallic acid equivalent and Trolox equivalent), antioxidant enzymes (SOD, GSHPx, GST, GR and CAT) and oxidative stress marker is represented in table: 2.

\section{CONCLUSION AND FUTURE SCOPE}

Study concludes that NAFLD participants indicates the presence of metabolic syndrome such as obesity, 
dyslipidaemia or/and elevated liver enzyme levels (SGPT, SGOT and GGT) compared to controls. Total antioxidant activity decreases in NAFLD condition which can be supported by values obtained for various antioxidant enzymes. Maximum decreased in values were obtained for CAT followed by GST, GSHPx and SOD whereas GR shows non-significant difference. Even though SGPT and SGOT do not drastically vary, antioxidant enzymes namely GST and CAT drastically changes compared to controls which can be used as surrogate markers of oxidative stress in NAFLD participants. Result of our study strengthens by the increase value obtained for oxidative stress marker which is considered as an important factor for pathogenesis of NAFLD.

The results of this study can be used to establish GST and CAT as markers for recognition of onset of NAFLD condition by planning and implementing future study after evaluating more samples from both the genders and at different geographical condition.

\section{LIMITATIONS}

Study is limited for non-alcoholic fatty liver condition. Grouping of the NAFLD condition on the basis of other disease/disorder conditions such as obesity, diabetes mellitus or any other associated condition to conclude lower and upper limits for all above parameters for both the genders is not included in present study.

\section{DISCLOSURE STATEMENT}

The authors have nothing to disclose.

\section{CONFLICT OF INTEREST STATEMENT}

The authors have no conflict of interest regarding the subject of the study.

Table 1. Anthropometric assessment, clinical and biochemical parameters of Controls and NAFLD participants

\begin{tabular}{|c|c|c|c|}
\hline Parameters & Controls $(n=52)$ & NAFLD $(n=48)$ & \multirow{2}{*}{$\begin{array}{c}\text { Statistical } \\
\text { Significance }\end{array}$} \\
\hline & Mean \pm S. E. (abnormal \%) & Mean \pm S. E. (abnormal \%) & \\
\hline \multicolumn{4}{|c|}{ Anthropometric assessment and clinical parameters } \\
\hline Age & $26.7 \pm 1.23$ years $(39 \mathrm{M} / 13 \mathrm{~F})$ & $41.71 \pm 1.71(43 \mathrm{M} / 5 \mathrm{~F})$ & $\mathrm{P}<0.0001$ \\
\hline BMI & $20.8 \pm 0.78(16 \%)$ & $30.02 \pm 0.92(79 \%)$ & $\mathrm{P}<0.0001$ \\
\hline Hypertension-(normal SBP/DBP- 120/80) & $120 / 80(0 \%)$ & $150 / 100(27 \%)$ & - \\
\hline Diabetic $(65-110 \mathrm{mg} / \mathrm{dl})$ & $85.87 \pm 1.06(0 \%)$ & $113.1 \pm 6.41(19 \%)$ & $\mathrm{P}=0.0001$ \\
\hline \multicolumn{4}{|c|}{ Biochemical parameters } \\
\hline Hemoglobin $(12-15 \mathrm{gm} / \mathrm{dl})$ & $13.27 \pm 0.18(9.6 \%)$ & $13.79 \pm 1.77(14.6 \%)$ & $\mathrm{P}=0.0983$ \\
\hline Total WBC Count $(4500-11000 / \mu \mathrm{l})$ & $7686.154 \pm 188.95(0 \%)$ & $7640 \pm 331.6(12.5 \%)$ & $\mathrm{P}=0.358$ \\
\hline Total RBC Count $(4.5-6)\left(* 10^{6} / \mathrm{microL}\right)$ & $4.51 \pm 0.084(0 \%)$ & $5.16 \pm 0.1(8 \%)$ & $\mathrm{P}<0.0001$ \\
\hline Platelets Count $(150,000-4,50,000 / \mu \mathrm{l})$ & $332,000 \pm 108000(0 \%)$ & $289000 \pm 126000(10 \%)$ & $\mathrm{P}=0.0025$ \\
\hline Total Protein $(\mathrm{gm} / \mathrm{dl})(6-8.5 \mathrm{gm} / \mathrm{dl})$ & $7.86 \pm 0.03(0 \%)$ & $7.48 \pm 0.9(0 \%)$ & $\mathrm{P}=0.0002$ \\
\hline Albumin $(\mathrm{gm} / \mathrm{dl})(3.2-5 \mathrm{gm} / \mathrm{dl})$ & $4.64 \pm 0.02(0 \%)$ & $4.35 \pm 0.05(0 \%)$ & $\mathrm{P}<0.0001$ \\
\hline \multicolumn{4}{|c|}{ Lipid parameters } \\
\hline Cholesterol $(150-200 \mathrm{mg} / \mathrm{dl})$ & $156.67 \pm 3.62(0 \%)$ & $206.45 \pm 5.950(50 \%)$ & $\mathrm{P}<0.0001$ \\
\hline Triglyceride $(40-140 \mathrm{mg} / \mathrm{dl})$ & $80.58 \pm 3.35(0 \%)$ & $185.16 \pm 17.67(52 \%)$ & $\mathrm{P}<0.0001$ \\
\hline HDL $(40-50 \mathrm{mg} / \mathrm{dl})$ & $46.6 \pm 1.39(0 \%)$ & $45.56 \pm 2.59(42 \%)$ & $\mathrm{P}=0.7225$ \\
\hline LDL $(<130 \mathrm{mg} / \mathrm{dl})$ & $93.61 \pm 3.76(0 \%)$ & $128.69 \pm 5.51(4 \%)$ & $\mathrm{P}<0.0001$ \\
\hline \multicolumn{4}{|c|}{ Liver Function Test } \\
\hline SGPT (5-49 U/1) & $16.96 \pm 1.09(0 \%)$ & $58.96 \pm 8.13(48 \%)$ & $\mathrm{P}<0.0001$ \\
\hline SGOT (12-45 U/l) & $18.23 \pm 0.71(0 \%)$ & $49.87 \pm 6.13(48 \%)$ & $\mathrm{P}<0.0001$ \\
\hline GGT (0-49 U/l) & $17.56 \pm 0.87(0 \%)$ & $97.65 \pm 41.95(29 \%)$ & $\mathrm{p}=0.0005$ \\
\hline ALP (30-141 U/1 ) & $64.63 \pm 2.97(0 \%)$ & $109.45 \pm 8.56(12.5 \%)$ & $\mathrm{P}<0.0001$ \\
\hline
\end{tabular}




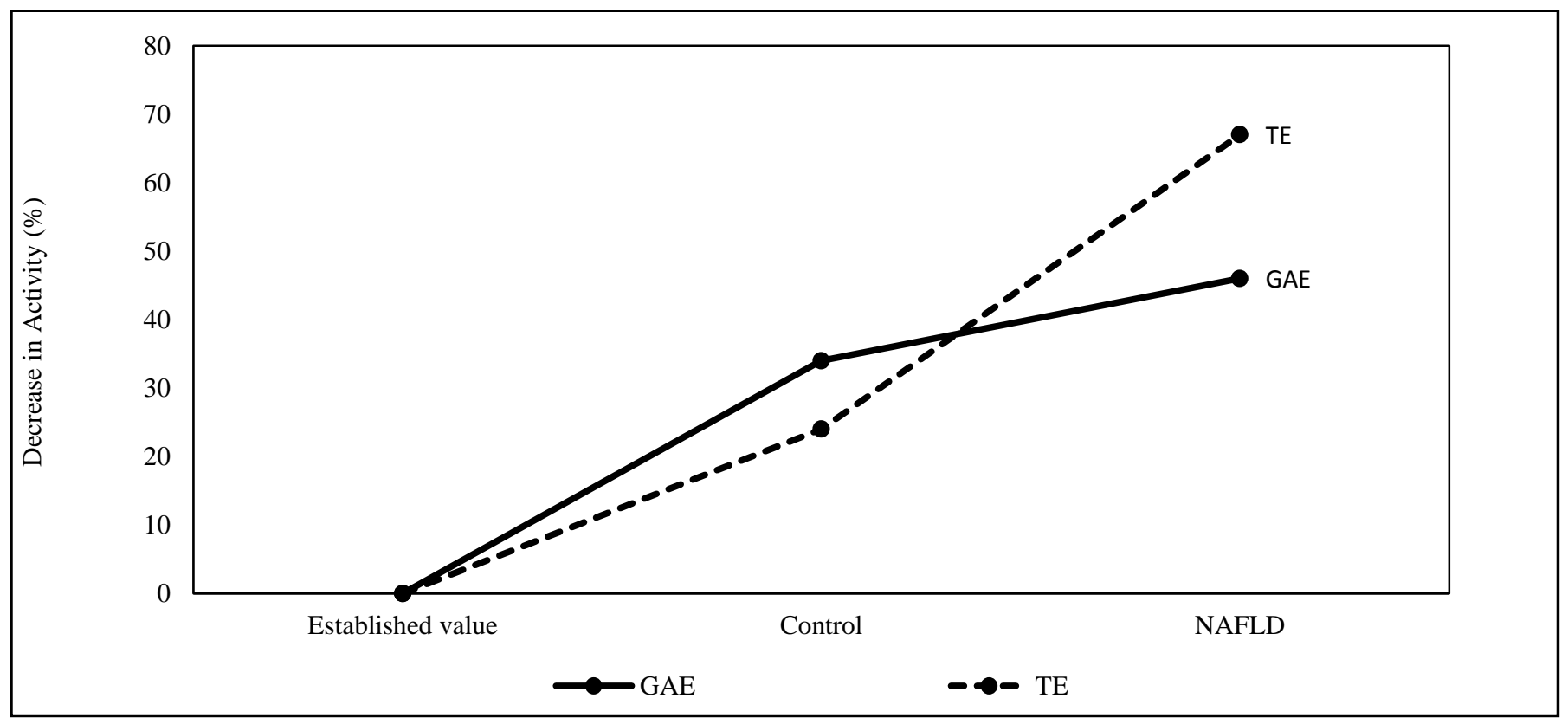

Figure: 1. Total antioxidant activity (Gallic acid equivalent and Trolox equivalent) of NAFLD participants compared to control and established value.

GAE: Gallic acid equivalent, $\boldsymbol{T E}:$ Trolox equivalent

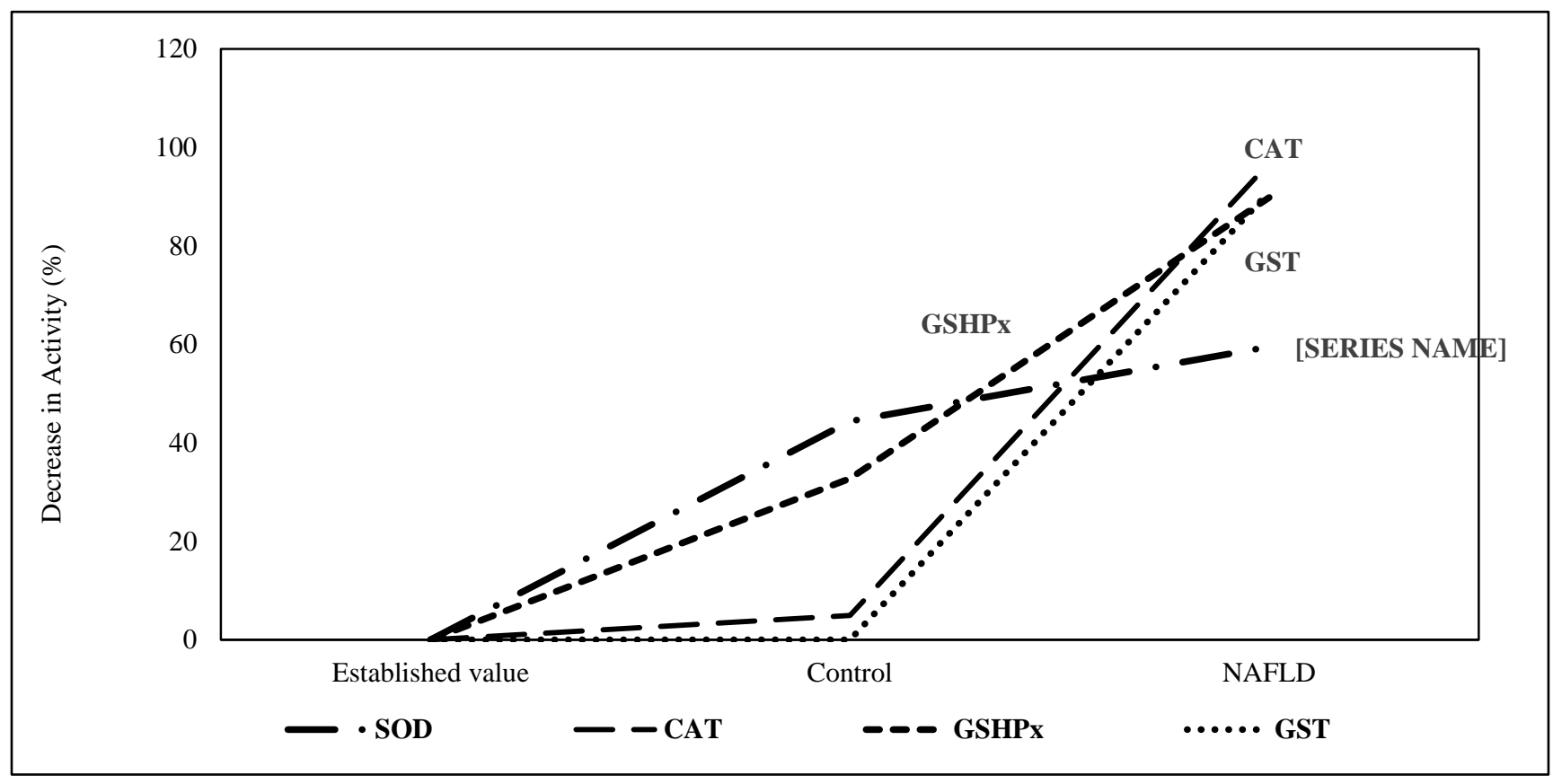

Figure: 2. Antioxidant enzymes level (SOD, CAT, GSHPx and GST) of NAFLD participants compared to control and established value. 


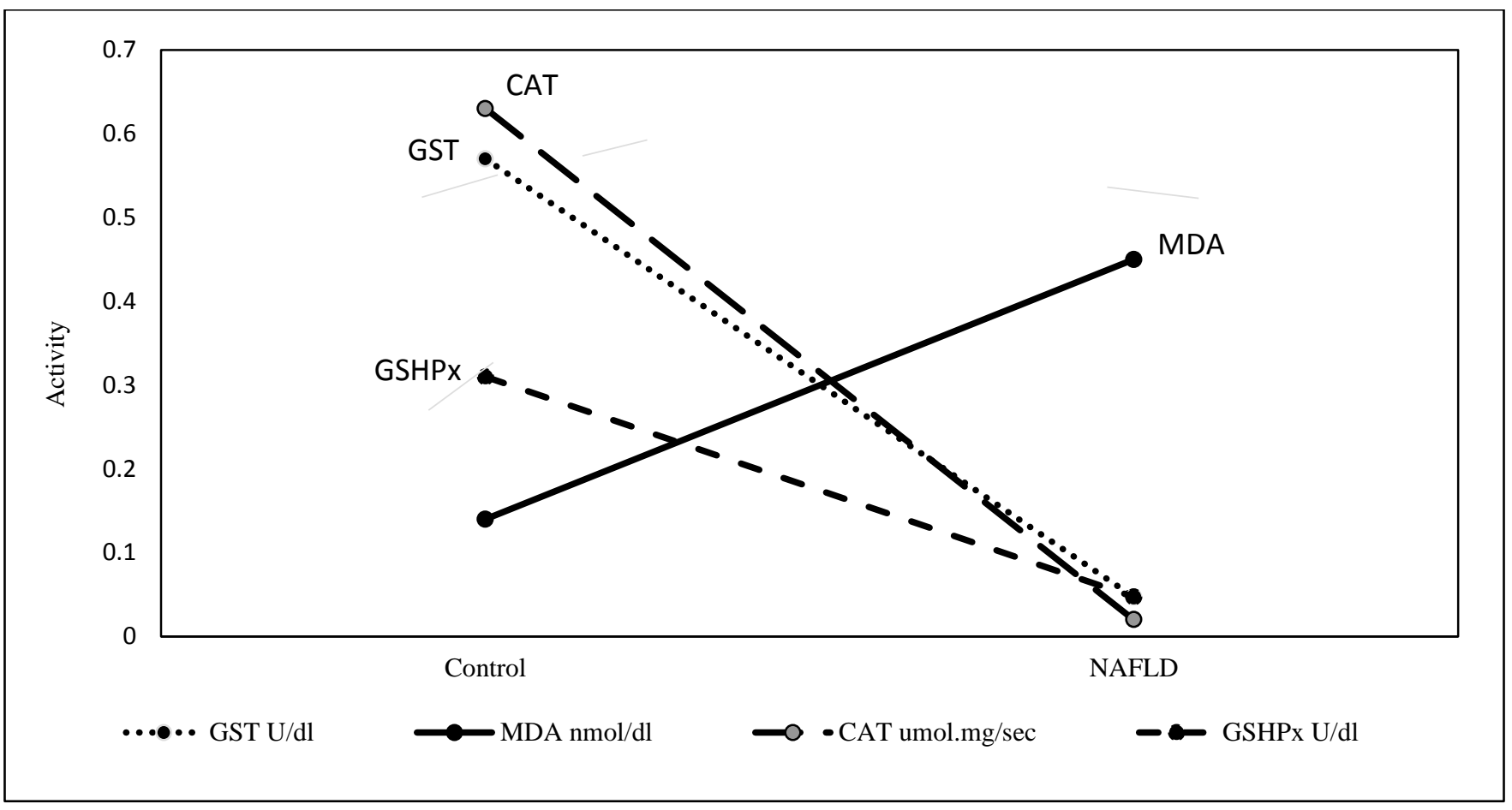

Figure:3. Correlation of antioxidant enzymes (GSHPx, GST and CAT) with oxidative stress marker (MDA)

Table 2: Statistical analysis for Antioxidant parameters and MDA level of controls and NAFLD participants

\begin{tabular}{|c|cc|}
\hline Parameters & $\begin{array}{c}\text { Statistical Significance } \\
\text { Controls Vs. NAFLD participants }\end{array}$ \\
\hline \multicolumn{3}{|c|}{ Total Antioxidant Activity } \\
\hline GAE & $\mathrm{p}=0.0008$ \\
\hline TE & $\mathrm{P}<0.0001$ \\
\hline SOD & Antioxidant Enzymes \\
\hline GSHPx & $\mathrm{p}=0.0023$ \\
\hline GST & $\mathrm{P}<0.0001$ \\
\hline CAT & $\mathrm{P}<0.0001$ \\
\hline GR & $\mathrm{P}<0.0001$ \\
\hline \multicolumn{3}{|c|}{ Oxidative Stress Marker } \\
\hline
\end{tabular}

\section{ACKNOWLEDGMENT}

The authors would like to thank all the participants for participating in the study. We thank principal of our institute to provide support and laboratory facilities, N. D. Patel (M.D., D. N. B. - Gastroenterologist) to screen out appropriate participants for the study and S. Patel (Sanjay Laboratory) for blood sampling. We also thankful to Professor K. Tiwari and J. G. Shah for helping in statistical analysis.

\section{AUTHOR CONTRIBUTION}

H. J. Shah, A. P. Thakkar and N. D. Patel had made efforts to plan out the objectives of the study.
H. J. Shah had guided for the analytical work and interpreted the result of the study.

A. P. Thakkar had collected informed consent from the participants and analysed the parameters from the collected blood samples penetrating to this work. Effort was made to standardize each protocol in our laboratory and computerised the data.

N. D. Patel had screen out appropriate participants for the study and guided as per the need.

J. G. Shah (Statistician) had carried out statistical analysis.

We all together worked for the preparation of the manuscript. 


\section{REFERENCES}

[1]. S. McPherson, T. Hardy, E. Henderson, A.D. Burt, C.P. Day, Q.M. Anstee. "Evidence of NAFLD progression from steatosis to fibrosing-steatohepatitis using paired biopsies: Implications for prognosis and clinical management", Journal of Hepatology, Vol. 62, pp. 1148-1155, 2015.

[2]. C.D. Byrne, G. Targher. "NAFLD: A multisystem disease", Journal of Hepatology, Vol. 62, pp. S47-S64, 2015.

[3]. S.F. Assimakopoulos, C. Gogos, C. Labropoulou-Karatza. "Could antioxidants be the "magic pill" for cirrhosis-related complications? A pathophysiological appraisal". Med Hypotheses, Vol. 77, Issue 3, pp. 419-423, 2011.

[4]. A. Duseja, "Non-alcoholic fatty liver disease in India - a lot done yet more required!'” Indian J Gastroenterol, Vol. 29, pp.217-225, 2010.

[5]. L.A. Adams, P. Angulo, K. Lindor, "Non-alcoholic fatty liver disease". CMAJ, Vol. 29, Issue 172 (7), pp. 899-905, 2005.

[6]. E. Fitzpatrick, A. Dhawan, "Noninvasive biomarkers in nonalcoholic fatty liver disease: current status and a glimpse of the future". World J Gastroenterol, Vol. 21, Issue 20(31), pp.1085110863, 2014.

[7]. D. Preiss, N. Sattar, "Non-alcoholic fatty liver disease: an overview of prevalence diagnosis pathogenesis and treatment considerations". Clinical Science, Vol. 115, pp. 141-150, 2008.

[8]. P. Angulo, "Obesity and Nonalcoholic Fatty Liver Disease", Nutrition Reviews, Vol. 65, Issue 6, pp. S57-S63, 2007.

[9]. P. Paschos, K Paletas, "Non-alcoholic fatty liver disease and metabolic syndrome", Hippokratia, Vol. 13, Issue 1, pp. 9-19, 2009.

[10]. J.K. Dowman, J. W. Tomlinson, P. N. Newsome, "Pathogenesis of non-alcoholic fatty liver disease”, Q J Med, Issue 103, pp. 7183, 2010

[11]. B. Yilmaz, K. Sahin, H. Bilen, I.H. Bahcecioglu, B. Bilir, S. Ashraf, K.J. Halazun, O. Kucuk, et al. "Carotenoids and nonalcoholic fatty liver disease”, HepatoBiliary Surg Nutr, Vol. 4, Issue 3, pp. 161-171, 2015.

[12]. A.A. Salgado, L.D. Carvalho, A.C. Oliveira, V.N. Santos, J.G. Vieira, E.R. Parise, "Insulin resistance index (HOMA-IR) in the differentiation of patients with non-alcoholic fatty liver disease and healthy individuals", Arq Gastroenterol, Vol. 47, Issue 2, pp. 165-169, 2010.

[13]. Sha Li, Hor-Yue Tan, NingWang, Zhang-Jin Zhang, Lixing Lao, Chi-WoonWong, Yibin Feng, et al. The Role of Oxidative Stress and Antioxidants in Liver Diseases. Int. J. Mol. Sci. 2015; 16: 26087-26124.

[14]. G.C. Farrell, C.Z. Larter, "Nonalcoholic Fatty Liver Disease: From Steatosis to Cirrhosis", Hepatology, Vol. 43, pp. S99-S112, 2006.

[15]. M. Percival, Antioxidants, Clinical Nutrition Insights, pp. 1-4.

[16]. N. Sapojnikova, N. Asatiani, T. Kartvelishvili, I. Kalandadze, A. Tsiskaridze, "Plasma antioxidant activity as a marker for a favorable outcome in acute ischemic stroke", Antioxidant Enzyme, pp. 142-168, 2012.

[17]. M.M. Al-Shahrani, G.S. Zaman, M. Amanullah, "Measurement of antioxidant activity in selected food products and neutraceuticals", J. Nutr Food Sci., Vol. 3, Issue 3, pp. 1-6, 2013.

[18]. M. Koruk, S. Taysi, M.C. Savas, O. Yilmaz, F. Akcay, M. Karakok, "Oxidative stress and enzymatic antioxidant status in patients with nonalcoholic steatohepatitis". Annals of Clinical \& Laboratory Science, Vol. 34, Issue 1, pp. 57-62, 2004.

[19]. E.A. Nantia, F.P. Manfo, N.S. Beboy, P.F. Moundipa. "In vitro antioxidant activity of the methanol extract of Basella alba $L$ (Basellaceae) in rat testicular homogenate". Oxidant Antioxidant Med Sci., Vol. 2, Issue 2, pp.131-136, 2013.
[20]. K.P. Jaiswal, A. Sarsavan, R.K. Chaudhary, S.A. Ali, M.K. Tembre, "The etiological features and treatment of vitiligo : A pilot study prospective to Indian scenario", International Journal of Scientific Research in Biological Science, Vol-1, Issue-1, pp.10-17, 2014.

[21]. I.A. Leclercq, "Antioxidant defence mechanisms: new players in the pathogenesis of non-alcoholic steatohepatitis?, Clinical Science, Vol. 106, pp. 235-237, 2004.

[22]. N.A. Ismail, S.H. Okasha, A. Dhawan, A.M. Abdel Rahman, N.A. Hamid, O. Shaker, "Glutathione peroxidase superoxide dismutase and catalase activities in children with chronic hepatitis". Advances in Bioscience and Biotechnology, Vol. 3, pp. 972-977, 2012.

[23]. G. Shiota, H. Tsuchiya. "Pathophysiology of NASH: Insulin resistant free fatty acids and oxidative stress", J. Clin. Biochem. Nutr, Vol. 38, pp. 127-132, 2006.

[24]. C.P. Oliveira, A.M. Coelho, H.V. Barbeiro, V.M. Lima, F. Soriano, C. Ribeiro, N.A. Molan, V.A. Alves, H.P. Souza, M.C. Machado, F.J. Carrilho, "Liver mitochondrial dysfunction and oxidative stress in the pathogenesis of experimental nonalcoholic fatty liver disease”, Braz J. Med. Biol. Res. Vol. 39, Issue 2, pp. 189-194, 2006.

[25]. Wen-Ce Zhou, Quan-Bao Zhang, Liang Qiao. Pathogenesis of liver cirrhosis, World J Gastroenterol, Vol. 21, Issue 20(23), pp. 7312-7324, 2014.

[26]. I. Shimizu, N. Shimamoto, K. Saiki, M. Furujo, K. Osawa. "Lipid peroxidation in hepatic fibrosis. In tech open sciencelopen minds", Kanagawa: Japan, pp. 483-492, 2012.

[27]. O. Pirgon, H. Bilgin, F. Cekmez, H. Kurku, B.N. Dundar, "Association between Insulin resistant and oxidative stress parameters in obese adolescents with non alcoholic fatty liver disease", J. Clin Res Pediatr Endocrinol; Vol. 5, Issue 1, pp. 3339,2013.

[28]. R. Kumar, S. Prakash, S. Chhabra, V. Singla, K. Madan, D. Gupta, S.K. Panda, S. Kanal and S.K. Acharya, "Association of pro-inflammatory cytokines, adipokines and oxidative stress with insulin resistant and non alcoholic fatty liver disease", Indian $\mathrm{J}$ Med Res; Vol. 136, pp. 229-36, 2012.

[29]. Z. Yesilova, H. Yaman., C. Oktenli, A. Ozcan, A. Uygun, E. Cakir, S.Y. Sanisoglu, A. Erdil, Y. Ates, M. Aslan, U. Musabak, M.K. Erbil, N. Karaeren and K. Dagalp, "Systemic Markers of Lipid Peroxidation and Antioxidants in Patients with Nonalcoholic Fatty Liver Disease", The American Jr. of Gastroenterology, Vol. 100, pp. 850-855, 2005.

[30]. G. Baskol, M. Baskol and D. Kocer, "Oxidative stress and antioxidant defense in serum of pateints with non alcoholic steatohepatitis", Clinical Biochemistry, Vol. 40, pp. 776-780, 2007.

[31]. E. Koroglu, B. Canbakan, K. Atay, I. Hatemi, M. Tuncer, A. Dobrucali, A. Sonsuz, I. Gultepe, H. Senturk, "Role of oxidative stress and insulin resistance in disease severity of non alcoholic fatty liver disease", Turk J Gastroenterol, Vol. 27, pp. 361-366, 2016.

[32]. M. Notarnicola, V. Tutino, A.R. Osella, C. Bonfiglio, V. Guerra and M.G. Caruso, "Increased serum levels of oxidative stress markers in patients with liver steatosis", J. Liver, Vol. 2, Issue 3, pp. 1000127.

[33]. S. Saluja, K. Arora. "Overweight and obesity and its association with blood pressure levels amongst females of Bathinda, Punjab", India J. maternal child health physiological dept., Adesh institute of medical science ad research -Bathinda, Vol. 12, pp. 11- 13, 2010.

[34]. I.F. Benzie, J. J. Strains, "The ferric reducing ability of plasma (FRAP) as a measure of "antioxidant power": The FRAP assay", Anal Biochem, Vol. 239, pp.70-76, 1996. 
[35]. E. Beutler, "Red cell metabolism", A Manual of Biochemical Methods, $3^{\text {rd }}$ ed. Grune and Stratton Inc., New York, 1984.

[36]. D.E. Paglia, W.N. Valentine, "Studies on the quantitative and qualitative characterization of erythrocyte glutathione peroxidase", J. Lab Clin. Med, Vol. 70, Issue 1, pp.158-169, 1967.

[37]. I. Carlbeg, B. Mannervik, J. Biol. Chem., Vol. 250, pp. 54755480,1975

[38]. H. Aebi, "Catalase in vitro methods", Enzymol, Vol. 105, pp. 121-126, 1984.

[39]. K. Prabhu, P.G. Bhat, D.M. Vasudevan, "Can serum glutathiones-transferase levels in carcinoma cervix be a predictor of radiation response?", Indian Jr. of Clinical Biochemistry, Vol. 20, Issue 1, pp. 95-97, 2005.

[40]. K. Asha, H.P. Kedilaya, K. Poomima, M. Cariappa, M. Nandini. "Oxidant and antioxidant status in vegetarians and fish eaters", Indian Journal of Clinical Biochemistry, Vol. 18, Issue 2, pp. 197205, 2003.

[41]. G.K. Kanji, "100 statistical tests", SAGE publication, $3^{\text {rd }}$ edition, London, Thousand Oaks, New Delhi, pp. 5-8, 2006.

[42]. L. Pacifico, E. Bonci, G. Andreoli, S. Romaggioli, R. D. Miscio, C.V. Lombardo, C. Chiesa, "Association of serum triglyceride-to$H D L$ cholesterol ratio with carotid artery intima-media thickness insulin resistance and non-alcoholic fatty liver disease in children and adolescents", Nutrition Metabolism \& Cardiovascular Diseases, pp. 1-7, 2014.

[43]. A.H. Kani, S.M. Alavian, A. Esmaillzadeh, P. Adibi, L. Azadbakht, "Dietary quality indices and biochemical parameters among patients with non-alcoholic fatty liver disease (NAFLD)", Hepatitis Monthly, Vol. 13, Issue 7, pp. 1-10, 2013.

[44]. S.L. Sharma, S.A. Chokshi, D. Desai, H. Mewada, A. Singh, "Non enzymatic antioxidants, malondialdehyde and total antioxidant activity as markers of oxidative stress in arthritis and rheumatoid arthritis", NHL Journal Of Medical Sciences, Vol. 2, Issue 1,pp. 57-60, 2013.

[45]. Y. Kambayashi, N.T. Binh, H.W. Asakura, Y. Hibino, Y. Hitomi, H. Nakamura, K. Ogino, "Efficient assay for total antioxidant capacity in human plasma using a 96-well microplate”, J. Clin. Biochem. Nutr., Vol. 44, pp. 46-51, 2009.

[46]. L.S. Bir, S. Demir, S. Rota, M. Koseoglu, "Increased serum malondialdehyde levels in chronic stage of ischemic stroke", Tohoku J. Exp. Med, Vol. 208, pp. 33-39, 2006.

[47]. Y. Guo, P. Li, Q. Guo, K. Shang, D. Yan, S. Du, Y. Lu, "Pathophysiology and Biomarkers in Acute Ischemic Stroke - A Review", Tropical Journal of Pharmaceutical Research, Vol. 12, Issue 6, pp. 1097-1105, 2013.

[48]. G.J. Beckett, J.D. Hayes, “Glutathione S-Transferase: Biomedical Applications", Advances in Clinical Chemistry, Vol. 30, pp. 281380, 1993.

[49]. K.M. Surapaneni, M. Jainu, "Comparative effect of pioglitazone quercetin and hydroxy citric acid on the status of lipid peroxidation and antioxidants in experimental non-alcoholic steatohepatitis", Journal of Physiology and Pharmacology, Vol. 65, Issue 1, pp. 67-74, 2014.

[50]. K. Madan, P. Bhardwaj, S. Thareja, S. Gupta, A. Saraya, "Oxidant stress and antioxidant status among patients with nonalcoholic fatty liver disease (NAFLD)", Journal of Clinical Gastroenterology, Vol. 40, Issue 10, pp. 930-935, 2006.

[51]. M.A. Hassanien, S.A. Abou-El-Noeman, E. Aboueladab, "Oxidative stress antioxidant and leptin status in patients with non-alcoholic steatohepatitis", European Journal of Academic Essays, Vol. 1, Issue 10, pp. 17-22, 2014.

[52]. D. Bonnefont-Rousselot, V. Ratziu, P. Giral, F. Charlotte, I. Beucler, T. Poynard, "Blood oxidative stress markers are unreliable markers of hepatic steatosis", Alimentary Pharmacology \& Therapeutics, Vol. 23, pp. 91-98, 2006.

[53]. K. Richter, T. Kietzmann, "Reactive oxygen species and fibrosis: further evidence of a significant liaison", Cell Tissue Res., Vol. 365, pp. 591-605, 2016.

[54]. M. Ekstedt, H. Hagstrom, P. Nasr, M. Fredrikson, P. Stal, S. Kechagias, R. Hultcrantz, "Fibrosis stage is the strongest predictor for disease specific mortality in NAFLD after up to 33 years of follow-up", Hepatology, pp. 1547-1554, 2015.

\section{AUTHORS PROFILE}

A.P. Thakkar pursued M.Sc. in Biochemistry from BRD school of Biosciences, Department of Biochemistry, Faculty of Sciences, Sardar Patel University, Vallabh Vidyanagar-Anand, Gujarat, India. She is currently working to pursue her $\mathrm{Ph}$. D. degree under the guidance of Dr. (Mrs.) H.J. shah in Department of Biochemistry at M. B. Patel Science

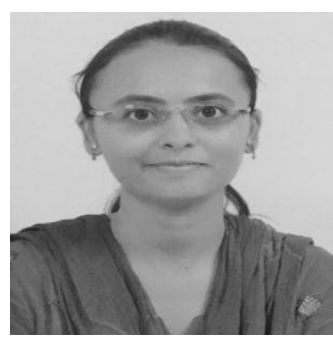

College, C. E. Society, Anand, Gujarat. She has published 5 research papers in reputed international and national journals. She has participated and presented more than 18 research papers in oral and poster presentation in various international and national conferences. She had received 6 awards in various international and national conferences for presentations. She had participated in 5 workshops including ICMR and GSBTM supported workshop on Ethical consideration in current research in human participants. Her main research work focuses on Nutritional, Biochemical and clinical parameters related to food, medicinal plants and human blood samples. She has 6 years of research experience. She has worked for UGC sponsored Major Research Project entitled "Dietary \& Nutritional status of college going adolescent students studying in selected colleges" for 2 years.

H.J. Shah pursued M.Sc. and Ph.D.in Foods and nutrition from Department of Foods and Nutrition, Faculty of Home Sciences, Sardar Patel University, Vallabh Vidyanagar-Anand, Gujarat, India. She is currently working as a Professor in Department of Biochemistry from July, 1982 at M. B. Patel Science College, C. E. Society, Anand, Gujarat. She has published 14 research papers in reputed international and national journals. She has participated and presented more than 25 research papers in oral and poster presentation in various international and national conferences. She had received 7 awards in various international and national conferences for presentations. She had participated in 6 workshops including ICMR and GSBTM supported workshop on Ethical consideration in current research in human participants. Her main research work focuses on Nutritional, Biochemical and clinical parameters related to food, medicinal plants and human blood samples. She has 34 years of teaching experience and 25 years of research experience. She is recognized as Ph.D. guide in Foods and nutrition and Biochemistry since 2008. She has guided 9 students for their research work. She act as a Chairman in Board of study in Biosciences, Sardar Patel University since 2011. She has Organized CBCS syllabi workshop. She is also a member of research 
committee for the faculty of home science and biosciences. She has received UGC sponsored Major Research Project entitled "Dietary \& Nutritional status of college going adolescent students studying in selected colleges" in 2008. She is acting as external examiner for various P. G. courses of Sardar Patel University and at U. G. level in various universities.

N.D. Patel pursued M.B.B.S. and M.D. (Gastroenterologist) from M. S. University, Baroda, Gujarat, India. He also pursued D.N.B. in gastroenterology from national board of examination, New Delhi. He is working as a consulting gastroenterologist, Hepatologist and therapeutic endoscopist at Jivandeep hospital, Anand, Gujarat, India since 2006. He has published more than 40 research papers in reputed international and national journals. He has presented more than 70 research papers in oral and poster presentation in various international and national conferences. He had participated in more than 100 international and national workshops, seminars and conferences.

J.G. Shah pursued B. E. (Electrical), MBA (Marketing), Ph. D (Management) from Sardar Patel University, Vallabh VidyanagarAnand, Gujarat, India. He is working as a senior manager at National Dairy Development Board (NDDB), Anand (Gujarat) since 1998. He has published 12 research papers in reputed

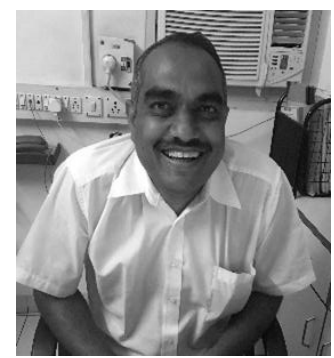
international and national journals. He has also published one book. He has participated and presented more than 30 research papers in oral and poster presentation in various international and national conferences. One of his paper has received best paper award from the reputed national journal for the year 2016. 